\title{
MORPHOLOGY OF THE RHESUS MONKEY OVARY NEAR THE TIME OF OVULATION
}

\author{
K. J. BETTERIDGE,* W. A. KELLY† AND J. H. MARSTON \\ Department of Anatomy, The Medical School, Birmingham 15
}

(Received 25th Fuly 1969)

Summary. The ovaries of sixty-seven rhesus monkeys were examined and photographed at known stages of 121 menstrual cycles. In eighty-three cycles, ovulation was diagnosed but, in thirty-two, the ovary showed a large Graafian follicle and, in six, there was no sign of follicular or luteal activity. The diagnosis of ovulation was confirmed in thirty-four cases by the recovery of an egg or cumulus clot and in another seventeen by histological examination of the ovary. Six diagnoses were supported by evidence from serial observations of the ovary, and a further twenty-six were based on single examinations. Fifteen ovaries were photographed both before and after ovulation.

The extremely variable appearance of proven ovulation points is illustrated and discussed. Morphological changes could not be detected on the surface of Graafian follicles within 24 to $48 \mathrm{hr}$ of ovulation and it was impossible to predict when they would rupture. The age of a corpus luteum could not be estimated from the gross morphology of its ovulation point. Occasionally, corpora lutea were found to persist into succeeding menstrual cycles in forms that could be mistaken for recent ovulation points.

The hazards of diagnosing ovulation by examining the ovaries at laparotomy can be reduced by making serial observations and photographic records.

\section{INTRODUCTION}

Although the rhesus monkey has been used for some 40 years in studies of reproductive physiology, criteria for the accurate diagnosis and precise timing of ovulation during its menstrual cycle have yet to be satisfactorily defined.

Hartman (1939a, b) timed about 300 natural ovulations in rhesus monkeys by rectal palpation of the ovaries: one third of these ovulations were subsequently confirmed by the recovery of eggs and embryos from the genital tract. After describing and illustrating the appearance of recent ovulation points, Hartman (1939a) emphasized the difficulty of using the gross morphology of the ovary to estimate when ovulation had occurred. He concluded that only the youngest corpus luteum (CL) could be aged by its gross appearance.

* Present address: Animal Diseases Research Institute, P.O. Box 1400, Hull, Quebec, Canada.

+ Present address: Department of Anatomy, The University, Bristol BS8 ITD.

† Present address: The Physiological Laboratory, Cambridge CB2 3EG. 
This paper reports our observations on the gross morphology of the ovaries in rhesus monkeys which were examined close to the expected time of ovulation in an attempt to record the actual process of ovulation, and also to see whether direct inspection of the ovaries at laparotomy was a reliable technique for diagnosing ovulation.

\section{METHODS}

Sixty-seven rhesus monkeys with an established menstrual periodicity were used: twenty-one animals were fitted with an intra-uterine device (IUD) which lay wholly within the uterine lumen. They were managed according to the system described by Eckstein, Kelly \& Marston (1969).

In the course of 121 menstrual cycles, 169 routine observations were made during mid-ventral laparotomy, which was usually performed between Days 10 and 20 of the menstrual cycle (Day 1 being the first day of menstrual bleeding). Four examinations were made on Day 8, one on Day 9 and another on Day 22. Forty-three monkeys were examined in more than one menstrual cycle, and repeat laparotomies were performed in thirty-four cycles. In a total of fifteen cycles, twelve monkeys were examined both before and after ovulation was diagnosed.

At laparotomy, which was carried out under pentobarbitone sodium anaesthesia (Nembutal, Abbot Laboratories), the ovaries were photographed at a magnification of $\times 1.5$ on Ektachrome X film (Kodak) using a Nikon F camera and a Medical Nikkor lens. The ovaries were then examined and their condition was accurately described to help in the interpretation of the colour transparencies. Some ovaries were also transilluminated with a minature lamp to simplify the identification of follicles and/or CL.

When ovulation was diagnosed, an attempt was usually made to recover the egg by flushing the Fallopian tube and uterus, either during the laparotomy or at a subsequent autopsy (Marston, Kelly \& Eckstein, 1969). One or both ovaries were removed from some animals for histological examination (Kelly, Marston \& Eckstein, 1969).

\section{RESULTS}

Table 1 summarizes the observations and evidence that ovulation had, in fact, occurred. The observations made on normal and IUD monkeys have been separated for the sake of accuracy. No differences between the two groups were detected and they were therefore considered as a single homogeneous population (Kelly et al., 1969).

Ovulation was regarded as proven when an egg or cumulus clot had been recovered from the genital tract, or when the ovary had been subjected to complete histological examination. Serial observations showing the change from a large Graafian follicle to a follicle with an apparent rupture point provided supporting, but not conclusive, evidence that ovulation had occurred. Diagnosis of ovulation by a single observation was achieved by comparison with proven cases of ovulation, a procedure which could not exclude the possibility of confusing an old CL with a recent ovulation point (see below). 


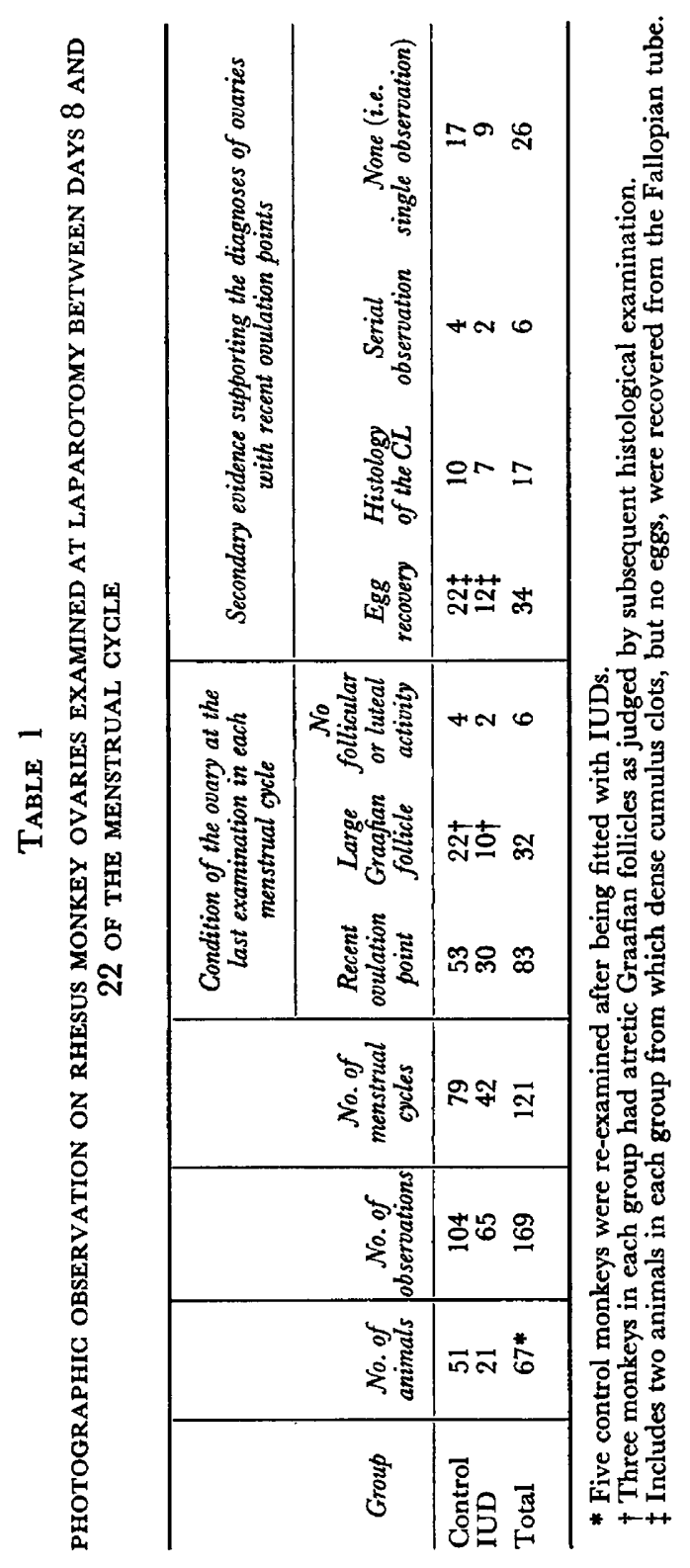




\section{Morphology of pre-ovulatory ovaries}

Thirty-two ovaries were thought to be in a pre-ovulatory state when they were examined and photographed. They all had a large ( 7 to $10 \mathrm{~mm}$ diameter), translucent Graafian follicle, which often seemed to occupy almost the entire substance of the ovary.

In fifteen additional cases, the ovaries were examined both before and after ovulation was diagnosed. The diagnosis of ovulation was proved in seven of them by egg recovery or histological examination. The interval between the two laparotomies was 1 day in two cases, 2 days in five, 3 days in two and from 4 to 10 days in six cases. Although the gradual growth of the Graafian follicle to a maximum pre-ovulatory diameter of 8 to $10 \mathrm{~mm}$ could be traced in this series, it was not possible to predict when ovulation would occur.

It was remarkable that in all forty-seven cases, the surface of the large Graafian follicle was completely unblemished. There was no indication of any petechial haemorrhages in the follicular wall nor of weakening or alteration in the surface which might have indicated the future ovulation point, as in other species (Pl. 1, Figs. 1 to 4 and Discussion). It seemed that any such pre-ovulatory change in the surface of the monkey Graafian follicle must be abrupt.

\section{Morphology of ovaries with recent ovulation points}

Fifty-one ovaries showed recent ovulation points which could be proved (Table 1). The appearance of these ovulation points was very variable (Pl. 1, Figs. 2, 4 to 8; Pl. 2, Figs. 9 to 12), ranging from prominent eruptions (Pl. 1, Figs. 2 and 7; Pl. 2, Fig. 9) to relatively slight marks on the ovarian surface (Pl. 1, Fig. 5). Some ovulation points were covered by a clear membrane containing prominent blood vessels (Pl. 1, Fig. 6; Pl. 2, Fig. 10). The majority showed either a slight crater in the ovarian surface (Pl. 1, Fig. 8; Pl. 2, Fig. 12) or a flattened, perhaps slightly domed, red area (Pl. 1, Fig. 4); both of these types of ovulation point were found with and without signs of bleeding. Ovulation points could also show variation from cycle to cycle in the same ovary ( $\mathrm{Pl}$. 1, Figs. 4 and 5; Pl. 2, Figs. 11 and 12).

The ovulation points were so variable that any noticeable discontinuity in the

The figures on both plates are reproduced at a magnification of $\times 3$. Figs. 3 to 7,13 and 16 show ovaries from monkeys with IUDs. All other figures are from control animals.

\section{EXPLANATION OF PLATE 1}

Figs. 1 and 2. Graafian follicle on Day 14 and the ovulation point on Day 15 of the menstrual cycle. A one-cell egg in cumulus clot was recovered from the Fallopian tube on Day 15.

FIgs. 3 and 4. Graafian follicle on Day 14 and the ovulation point on Day 16. A one-cell egg in cumulus clot was recovered from the Fallopian tube on Day 16.

FIG. 5. Ovulation point on Day 15 when a one-cell egg in cumulus clot was recovered from the Fallopian tube. The same ovary is shown in Figs. 3 and 4 two cycles later.

FIG. 6. Ovulation point on Day 14 when a one-cell egg in cumulus clot was recovered from the Fallopian tube.

Fig. 7. Ovulation point on Day 14 when a one-cell egg in cumulus clot was recovered from the Fallopian tube.

FIG. 8. Ovulation point on Day 16 when a seven-cell egg was recovered from the Fallopian tube. 
PI.STE I
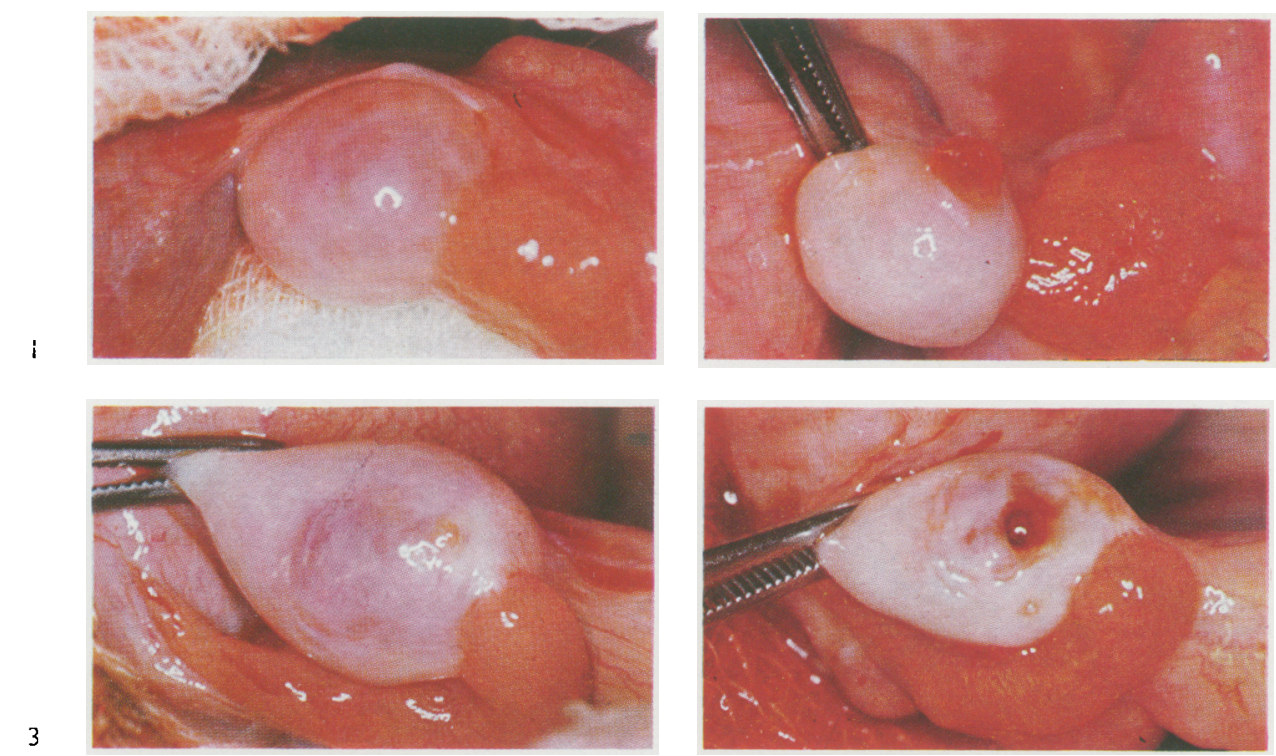

4
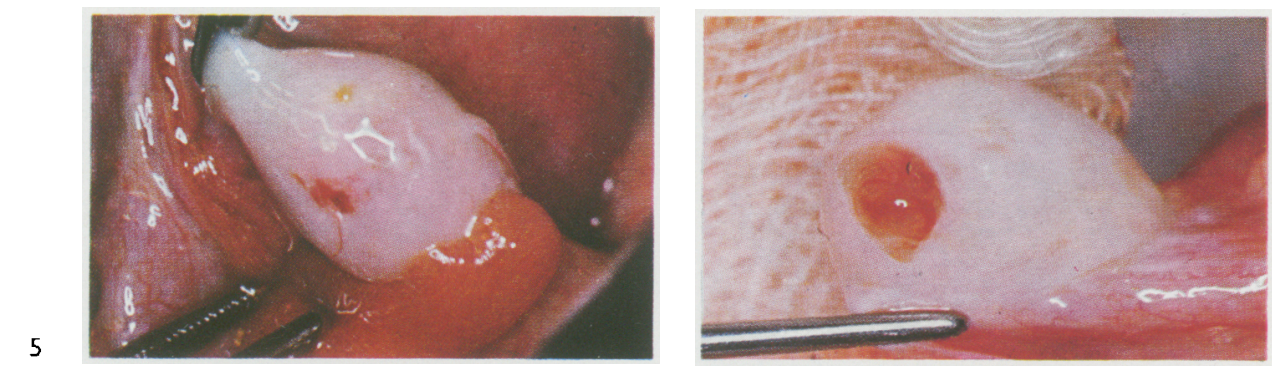

6
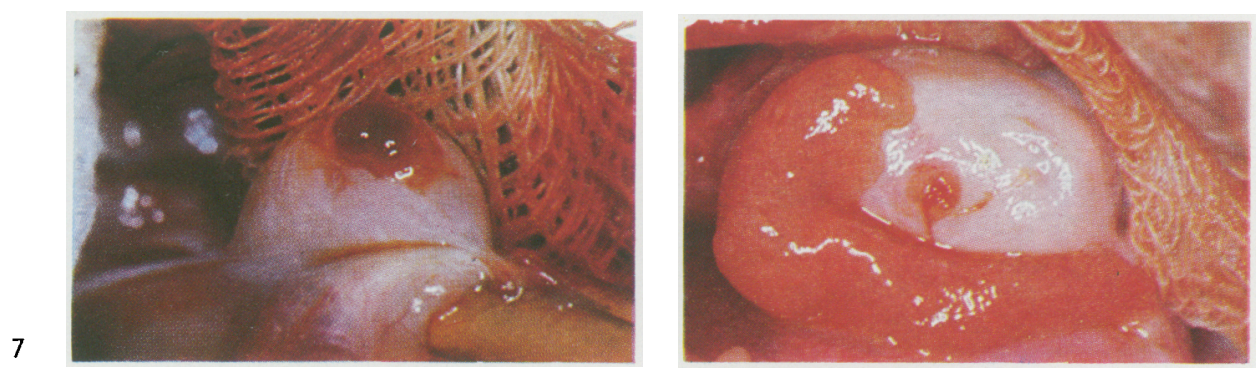
PI. TTE ?

9
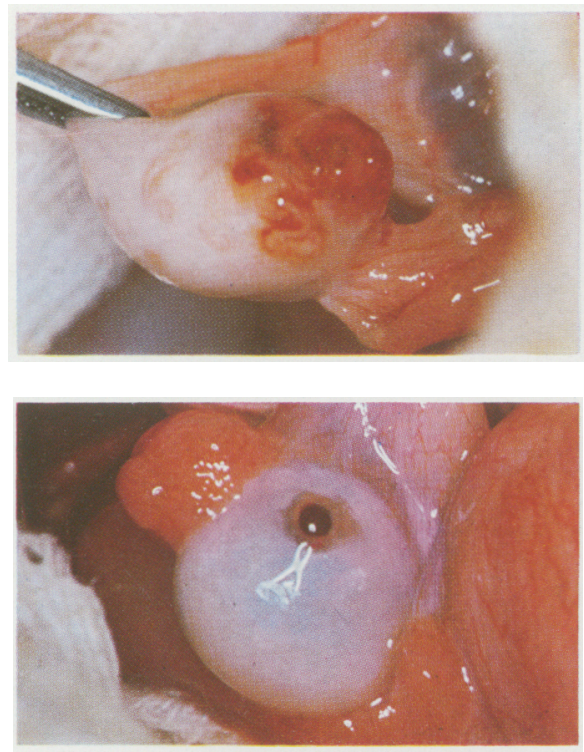

II

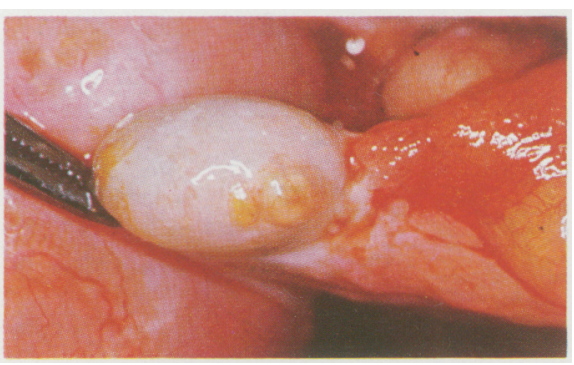

13

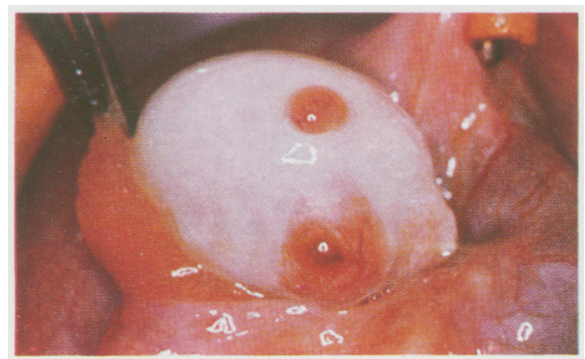

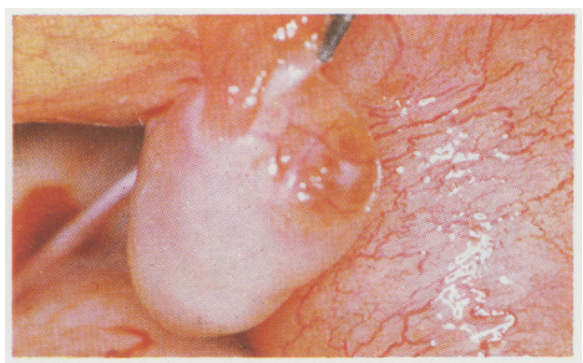

10

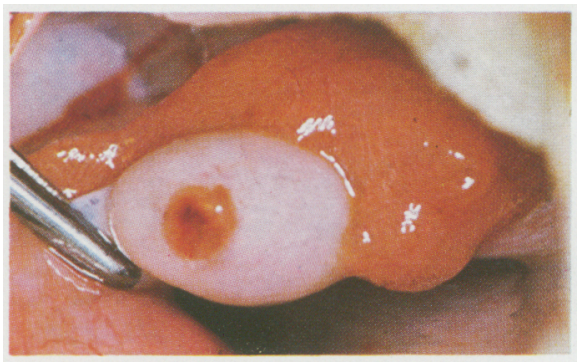

12

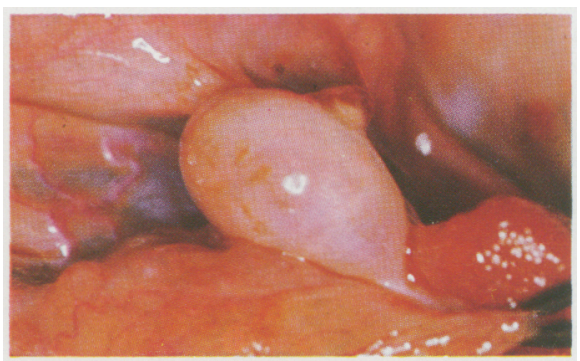

14

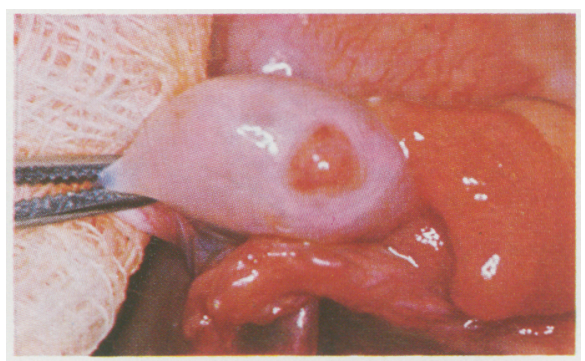

(Facing p. 457) 
ovarian surface had to be considered an ovulation point until this interpretation could be excluded. Two ovaries appeared to show large Graafian follicles in the process of ovulating (Pl. 2, Fig. 11), at least as judged by the morphological features noted in other species (cf. Discussion). In fact, both follicles had ruptured and the eggs were recovered from the Fallopian tubes.

The age of fifty-seven ovulation points could be estimated from either the timing of serial observations, the histological age of the CL (Corner, 1945; Kelly et al., 1969) or the appearance of the ovulated egg (Marston \& Kelly, in preparation). The estimated ages ranged from 1 to 8 days. It was impossible to estimate the age of an ovulation point, even the most recent one, from its gross appearance.

\section{Morphology of old corpora lutea}

Old cL could still be identified in ten of eleven ovaries examined one cycle after ovulation, and in four of seven ovaries after at least two cycles. The CL which could not be distinguished one cycle after its formation may have been displaced, or otherwise affected, by a Graafian follicle which had matured at almost the same site. Four of the one-cycle-old CL and one of the older ones could have been confused with fresh ovulation points (PI. 2, Figs. 14 to 16). These misleading CL were either red and protruding from the ovarian surface, or were covered with a clear membrane containing blood vessels. The old CL (Pl. 2, Fig. 16) was diagnosed as a recent ovulation point until previous photographs of the ovary were examined. Many old CL, however, were distinctly yellow (PI. 2, Fig. 13) and could not be mistaken for recent ovulation points.

\section{Diagnosis of ovulation by a single observation at laparotomy}

Twenty-six ovulation points were identified in this way: in appearance they were identical to the fifty-one proven ovulation points. In the majority of cases, it was not difficult to recognize that ovulation had recently occurred, especially if the ovulation point was open, bleeding, and showed a distinct raw edge. It was clear, however, that some diagnoses were difficult to make and could have been mistaken (see above). Eight ovaries had been photographed or carefully examined in the preceding menstrual cycle and so there was no doubt that the

\section{EXPLANATION OF PLATE 2}

FIG. 9. Ovulation point on Day 12 when a two-cell egg was recovered from the Fallopian tube.

Fig. 10. Ovulation point on Day 15 when a nine-cell egg was recovered from the uterus. Fig. 11. Ovulation point on Day 13. The ovary was originally thought to be in a preovulatory condition, but its appearance had not changed 1 day later when a four-cell egg was recovered from the Fallopian tube.

FIG. 12. Ovulation point on Day 12 when a one-cell egg was recovered from the Fallopian tube. This ovary is the one shown in Fig. 11 during the previous menstrual cycle.

Fig. 13. The GL from the ovulation in Fig. 7 seen on Day 13 one cycle after its formation. FIG. 14. The CL from the ovulation in Fig. 2, still red and protuberant one cycle after its formation. It was still visible as a small red pimple three cycles after its formation.

Fig. 15. Ovary on Day 15: the lower structure is a recent ovulation point, but the upper is a CL formed two cycles previously.

Fig. 16. Corpus luteum on Day 14: it was erroneously diagnosed as a recent ovulation point before photographs showing its origin in the previous cycle were consulted. 
ovulation point had developed during the current cycle. Reference to accurate records of the ovary's appearance in the previous cycle offered the only accurate and practicable way of diagnosing ovulation by a single observation at laparotomy.

\section{DISCUSSION}

The present study has emphasized the extent to which recent ovulation points in rhesus monkeys can vary in appearance, a fact that has long been recognized (Hartman, 1939a, b) but has not, hitherto, been adequately illustrated. We have not observed any changes in mature Graafian follicles which might indicate when ovulation would occur. In species in which the time intervals between ovulation and the formation of a stigma on the Graafian follicle are known, they are invariably short. In the rat, for instance, the stigma grows and ruptures within 3 to $5 \mathrm{~min}$ (Blandau, 1955); it also grows 'somewhat rapidly' in the rabbit (Walton \& Hammond, 1928) and the secondary cone, through which rupture actually occurs, develops in approximately 2 min (Betteridge, unpublished). The stigma is not seen until $1 \mathrm{hr}$ before rupture in the sheep, and the secondary cone again develops within a few minutes (McKenzie \& Terril, 1937). In women, the 'secondary cystic enlargement' of the follicle is said to occupy the last $6 \mathrm{hr}$ before ovulation (Rock, 1965); and in two cases observed by Doyle (1951), rupture of the follicle occurred through a clear, non-protuberant area in the follicle's wall. Any pre-ovulatory changes in the rhesus monkey's Graafian follicle which may be similar to these processes remain to be recorded and our observation that they are not to be found 24 to $48 \mathrm{hr}$ before ovulation does not agree with the results reported by Johansson, Neill \& Knobil (1968). These authors noted that 'the stigma can be found within two days before ovulation', and that 'its appearance varies considerably from follicle to follicle'. They illustrated the appearance of Graafian follicles which showed stigmata and were thought to be pre-ovulatory (their Figs. 3b and 3e) with photographs that are remarkably similar to our photographs of proven ovulation points (Plates 1 and 2). It seems probable that Johansson et al. (1968) mistakenly identified fresh ovulation points as Graafian follicles showing preovulatory stigmata and did not observe a 'rather clear picture of the transitional events which lead to the formation of a corpus luteum', but only the gross difference between pre-ovulatory follicles (their Figs. $3 \mathrm{a}$ and 3d) and follicles which had already ruptured (their Figs. $3 b, c$, e and $\mathbf{f}$ ).

If their monkeys were in fact ovulating earlier than Johansson and his colleagues supposed, the precise relationship between plasma progestin levels and ovulation will need to be re-interpreted for this species. Our study was made before publication of the Pittsburgh data and we, unfortunately, have no progestin determinations with which to make such a correlation.

\section{ACKNOWLEDGMENTS}

This work was supported by grants from the Ford Foundation, New York, to Professor Sir Solly Zuckerman, O.M., K.C.B., F.R.s., and Dr P. Eckstein of this 
Department, and was reported in full to the Annual Conference of the Society for the Study of Fertility, 1967.

We are grateful to Miss Margaret Giles for her expert assistance, and to $\mathrm{Mr}$ H. Smith, Mr F. James and Mr G. Tonks for their invaluable help in caring for the monkeys.

\section{REFERENCES}

BLANdAu, R. J. (1955) Ovulation in the living albino rat. Fert. Steril. 6, 391.

Corner, G. W. (1945) Development, organisation and breakdown of the corpus luteum in the rhesus monkey. Contr. Embryol. 31, 117.

DoyLe, J. B. (1951) Exploratory culdotomy for observation of tubo-ovarian physiology at ovulation time. Fert. Steril. 2, 474.

Eckstein, P., Kelly, W. A. \& Marston, J. H. (1969) Effect of an intra-uterine device on menstrual periodicity in the rhesus monkey. F. Reprod. Fert. 19, 133.

HARTMAN, G. G. (1939a) Studies on reproduction in the monkey and their bearing on gynecology and anthropology. Endocrinology, 25, 670.

Hartman, C. G. (1939b) Ovulation, fertilization and the transport and viability of eggs and spermatozoa. In: Sex and Internal Secretions, 2nd edn, pp. 630-719. Ed. E. Allen. Williams \& Wilkins, Baltimore.

Johansson, E. D. B., Neill, J. D. \& KNoBil, E. (1968) Peri-ovulatory progesterone concentration in the peripheral plasma of the rhesus monkey with a methodologic note on the detection of ovulation. Endocrinology, 82, 143.

Ketly, W. A., Marston, J. H. \& Eckstein, P. (1969) Effect of an intra-uterine device on conception and ovulation in the rhesus monkey. F. Reprod. Fert. 19, 143.

McKenzie, F. F. \& Terril, G. E. (1937) Estrus, ovulation and related phenomena in the ewe. Bull. Mo. agric. Exp. Stn, 264.

Marston, J. H., Keliy, W. A. \& Eckstein, P. (1969) Effect of an intra-uterine device on gamete transport and fertilization in the rhesus monkey. F. Reprod. Fert. 19, 149.

Rock, J. (1965) Foretelling the time of ovulation. In: Human Ovulation, pp. 17-20. Ed. C. S. Keefer. Little, New York.

Walton, A. \& Hammond, J. (1928) Observations on ovulation in the rabbit. Br. F. exp. Biol. 6, 190. 